\title{
NILAI PENDIDIKAN DALAM FOLKLOR ASPEK KAPAMALIAN DI DESA TANJUNGWANGI KECAMATAN CICALENGKA KABUPATEN BANDUNG
}

\author{
Diani Permasih, Dedi Koswara, Dede Kosasih \\ Departemen Pendidikan Bahasa Daerah FPBS UPI \\ Pos-el: dianipermasih2907@gmail.com, dedi.koswara@upi.edu, dede.kosasih@upi.edu
}

\begin{abstract}
Abstrak
Latar belakang penelitian ini didasari oleh berkurangnya penggunaan kapamalian sebagai alat untuk mendidik dan menjaga keselamatan diri oleh masyarakat. Skripsi ini merupakan penelitian yang bertujuan untuk menginventarisasi kapamalian yang ada di Desa Tanjungwangi Kecamatan Cicalengka Kabupaten Bandung.Penelitian ini menggunakan metode deskriptif analitik dengan teknik observasi dan wawancara. Data yang berhasil dikumpulkan lalu dideskripsikan, dianalisis berdasarkan nilai pendidikan yang mencakup nilai moral, nilai sosial, nilai agama, dan analisis unsur semiotiknya. Sumber data diambil dari lima narasumber.Kapamalian yang terkumpul dari hasil wawancara dengan narasumber adalah sebanyak 94 kapamalian.Aneka kapamalian tersebut dideskripsikan berdasarkan hasil wawancara. Aspek-aspek yang dianalisis dalam penelitian ini adalah 1) deskripsi arti kapamalian, 2) analisis nilai pendidikan yang terdapat dalam kapamalian, serta 3) unsur semiotik yang terdapat dalam kapamalian tersebut.Berdasarkan penelitian yang dilakukan, diharapkan adanya upaya pemerintah dalam meninventarisir aspek-aspek kapamalian yang tersebar di masyarakat, sehingga kapamalian tersebut masih dijadikan alat atau media dalam mendidik anak.
\end{abstract}

Kata kunci:kapamalian, nilai pendidikan, semiotik,

\section{EDUCATION VALUE IN FOLKLORE ASPECTS OF SUPERSTITION KAPAMALIAN EXISTEDIN TANJUNGWANGI CICALENGKABANDUNG REGENCY}

\begin{abstract}
The background of this research is based on the rare use of kapamalian (superstition) as a tool to educate and protect one self. This research paper is aimed to collect kapamalian (superstitions) which exist in Tanjungwangi, Cicalengka Bandung regency. The purpose of the research is for describing the meaning, the function, analyzing the education value and semiotic approach of the superstitions (kapamalian). This research was conducted by using descriptive analytic method with observation and interview as the technics of collecting data. The data gained then described, analyzed based on the education values, and its semiotic elements. From one village, five sample informants were chosen. From the interview session, it is found that there are 94 kapamalian, and then those kapamalian were described based on the interview between the researcher and the informants. The aspects analyzed in this research are 1) meaning description of kapamalian, 2) analysis of education value lies on kapamalian, and 3) semiotic features of those kapamalian. Based on the research, it is expected that there will be attempts from the government to preserve the kapamalian aspects spread in the society, so that the kapamalian still be able to use as a tool or media in educating children.
\end{abstract}

Keywords: kapamalian, education value, semiotic. 


\section{PENDAHULUAN}

Dalam kehidupan sehari-hari, manusia hidup bersamaan dengan kebudayaan. Manusia memiliki budaya dikarenakan manusia mempunyai akal dan fikiran. Akal dan fikiran yang dimiliki manusia adalah sebagai ciri yang membedakan dengan makhluk lainnya. Kebudayaan tersebut diciptakan serta digunakan oleh manusia itu sendiri. Kebudayaan akan terus tumbuh bersamaan dengan perkembangan jaman.

Koentjaraningrat (2009, hlm. 144), menyatakan bahwa kebudayaan merupakan sistem gagasan, tindakan dan hasil karya manusia dalam kehidupan masyarakat yang dimiliki oleh manusia melalui proses belajar. Kebudayaan sangat mempengaruhi terhadap nilai pendidikan masyarakatnya, begitupun sebaliknya pendidikan sangat berpengaruh terhadap perkembangan kebudayaan.Dengan pendidikan bisa membuat budaya-budaya yang ada berkembang dan tidak terbawa arus perkembangan jaman, serta nilai-nilai yang terkandung dalam budaya tentu berpengaruh terhadap perkembangan pendidikan.

Manusia adalah makhluk sosial, yang membutuhkan orang lain dalam menjalani kehidupannya. Seperti yang terkandung dalam lirik pupuh Pucung:

\section{Utamana jalma kudu loba batur}

Keur silih tulungan,

Silih titipkeun nya diri,

Budi akal lantaran ti padajalma

Oleh sebab itu, manusia hidup dalam satu kelompok yang bisa disebut dengan masyarakat.

Biasanya, dalam interaksi sosial bisa berdampak positif maupun negatif. Dampak negatif bisa mempengaruhi seseorang untuk melakukan hal-hal yang tidak sesuai dengan norma-norma agama serta norma-sorma sosial.Untuk menghindari pengaruh negatif yang ada di lingkungan, manusia membutuhkan sistem untuk mengurangi pengaruh negatiftersebut.Sistem yang menanggulangi pengaruh negatif itu berupa aturan norma, kaidah, hukum tertulis dan tidak tertulis.

Aturan yang tidak tertulis umumnya terdapat dalam budaya lokal yang salah satunya berupa aspek kapamalian, karena dalam budaya lokal tersebutmengandung nilai-nilai dan filosofi kehidupan.Dalam kapamalian, masyarakat Sunda dahulu menyampaikan fikiran, rasa, keinginan dalam bentuk lisan dengan cara halus (dibalibirkeun) agar masyarakat tidak merasa langsung dinaséhati.

Pamali merupakan bagian dari folklor. Menurut Jan Harold Brunvand (Danandjaya, 2007, hlm. 21) folklor terbagi menjadi tiga bagian, yaitu folklor lisan, folklor sebagian lisan, dan folklor non lisan. Folklor lisan yaitu folklor yang murni berbentuk lisan, yang di antaranya bahasa rakyat, ungkapan tradisional, pertanyaan tradisional, puisi rakyat, cerita prosa rakyat, dan lagu-lagu tradisional. Folklor sebagian lisan yaitu folklor yang bentuknya berupa campuran antara unsur lisan dengan unsur non lisan, yang di antaranya kepercayaan rakyat (tahayul), permainan rakyat, teater rakyat, tarian rakyat, adat istiadat, upacara, pesta rakyat. Folklor non lisan yaitu folklor yang bentuknya bukan lisan, walaupun cara membuatnya melalui lisan, yang di antaranya arsitektur rakyat, kerajinan tangan rakyat, pakaian, perhiasan, makanan, minuman, gerak isyarat tradisional, suara isarat tradisional, serta musik rakyat. Dari penggolongan diatas, jelas bahwa pamali termasuk ke dalam folklorsebagian lisan yang termasuk ke dalam genre kepercayaan rakyat.

Setiap masyarakat tentu memiliki kebudayaan masing-masing, salah satunya berupa kepercayaan rakyat. Kepercayaan rakyat di sini berupa pamali atau pantrangan. Kata pamali digunakan untuk hal-hal yang bersifat tabu.

Dalam kehidupan masyarakat Sunda, banyak terdapat bentuk kalimat-kalimat larangan/pantrangan, di antaranyakapamalian. 
Pamali menurut Danadibrata (2009, hlm.489) nyaéta larangan sepuh urang anu maksudna teu meunang ngalakukeun hiji pagawéan lantaran sok aya matakna.

Katapamali, ada yang mudah untuk diartikannya (walau hanya dikira-kira), tidak sedikit juga pamali yang susah diartikannya. Terkadang karena susah untuk diartikan, akhirnya dianggap sebagai lelucon belaka.Tidak ada bedanya dengan arti dongeng yang akhirnya menjadi arti lelucon, yaitu "ngabobodo budak céngéng" atau dalam bahasa Indonesia diartikan sebagai cerita yang dibuat untuk anak-anak cengeng. Padahal jika dilihat secara makna dan kefungsiannya, dongeng sangat kaya akan nilai-nilai pendidikan(Ruhimat, 2006, hlm. 41).

Nilai berarti harga (LBSS, 1995, hlm. 18; Satjadibrata, 2001, hal. 38). Di sini nilai bukan hanya diartikan sebagai harga yang dapat diukur dengan angka, tapi berupa hal yang berhubungan dengan norma kehidupan. Dalam norma-norma kehidupan tentu banyak sekali terdapat aturan-aturan dengan nilai-nilai pendidikan, mendidik anak berperilaku baik agar bisa patu terhadap norma-norma kehidupan. Pendidikan menurut Danadibrata (2009, hlm.39) adalah pembelajaran terhadap hal-hal kebaikan, memberi, mengajarkan mendidik, membimbing. Dapat disimpulkan bahwa nilai-nilai pendidikan adalah sebuah ajian, jampé, atau nilai-nilai yang didapatkan melalui pendidikan atau pengajaran yang bisa memberi manfaat agar manusia selalu ada di jalan kebaikan. Menurut Loree (Setiyadi, 2011, hlm. 29), nilai pendidikan terdiri dari nilai moral, nilai sosial, dan nilai agama.

Penelitian tentang aspek kapamalian terbilang penting untuk mengetahui seberapa besar dan banyak nilai pendidikan dalam kapamalian tersebut yang akhirnya mempengaruhi sikap dari masarakat pemakainya. Nilai-nilai yang terkandung dalam pamali tersebut tentunya akan sangat berpengaruh terhadap kehidupan masyarakat. oleh karena itu, pamali dijadikan alat untuk mendidik anak-anak oleh para orang tuanya. Salah satu dampak ketika kita mendidik anak dengan pamali atau dengan menakut-nakuti anak dengan hal yang membuat dia takut atau merugi, nantinya anak akan memperhatikan dan akhirnya dia merasa takut dan patuh kepada orang tuanya.

Dalam penelitian kapamalian ini, selain terdapat analisis tentang nilai pendidikan, juga dibahas tentang analisis dengan ulikan semiotik. Hal ini dikarenakan kapamalian mengandung makna yang tidak sesuai dengan arti sebenarnya atau multitafsir.

Zoest (dalam Santosa,1993, hlm. 3) menerangkan bahwa semiotik sebagai studi mengenai tanda-tanda dan semua hal yang berhubungan dengan cara yang digunakannya, hubungan dengan tanda yang lainnya, pengirim tanda tersebut, dan yang menerima tanda tersebut. Peirce menyebutkan bahwa sesuatu hal bisa disebut sebagai tanda jika mewakili sesuatu (Hoed, 2011, hlm. 19).

Dalam penelitian kali ini, digunakan teori semiotik Peirce, yang terdiri dari tanda ikon, indeks, dan simbol.

Berdasarkan penjelasan di atas, penelitian kali ini mempunyai tujuan untuk mendeskripsikan kapamalian, mengetahui arti dan fungsi dari kapamlian, menganalisis nilai-nilai pendidikan yang terkandung dalam kapamlian, serta menganalisis unsur semiotik yang ada dalam kapamalian tersebut.

\section{METODE}

Metode yang digunakan dalam penelitian kali ini adalah metode deskriptif analitik. Metode deskriptif analitik adalah metode yang mendeskripsikan serta menganalisis. Dengan menggunakan metode tersebut, diharapkan objek yang diteliti bisa diartikan secara maksimal (Ratna, 2010, hlm. 334). Metode penelitian deskriptif memusatkan peneliti untuk menyelesaikan masalah-masalah aktual yang muncul ketika melaksanakan penelitian. 
Metode deskriptif analitik digunakan untuk mendeskripsikan aspek kapamalian yang ada di wilayah Desa Tanjungwangi kecamatan Cicalengka. Data yang sudah dikumpulkan, lalu dianalisis mengenai nilai pendidikan yang terkandung di dalam nya, lalu dihubungkan dengan unsur-unsur semiotik yang ada dalam kapamalian tersebut.

Desain penelitian ini yaitu (1) identifikasi masalah (2) mengumpulkeun data (3) analisa masalah dan (4) kesimpulan.

Lokasi penelitian ini yaitu di Desa Tanjungwangi yang berada di Kecamatan Cicalengka Kabupaten Bandung. Dilihat dari topografi, kondisi wilayah Désa Tanjungwangi berupa daerah pegunungan. Desa tersebut merupakan desa terujung. Tapi walaupun begitu, desa tersebut termasuk desa yang mempunyai daya tarik tersendiri, terutama keadaan alamnya yang masih asri dan objek wisatanya yang terkenal yaitu Curug Cindulang dan KW (Kawasan Wisata).

Subjek dalam penelitian ini yaitu warga Desa Tanjungwangi Kecamatan Cicalengka Kabupaten Bandung, yang berumur 40 tahun keatas, serta hidup di desa tersebut dari sejak kecil sampai tuanya. Dari sumber tersebut, data yang dikumpulkan lalu dianalisis fungsi dan nilai pendidikannnya, serta dianalisis unsur semiotik yang terdapat dalam kapamalian tersebut.

Instrumen yang digunakan dalam penelitian ini terdiri dari pedoman observasi, padoman wawancara, serta media-media yang mendukung dalam proses penelitian ini yaitu kamera, alat perekam, dan kartu penelitian.

\section{HASIL DAN PEMBAHASAN}

Berdasarkan hasil penelitian, kapamalian yang terkumpul dari lima narasumber yang ada di Desa Tanjungwangi sebanyak 88 kapamalian. Kapamalian tersebut dideskripsikan arti dan fungsinya, dianalisis nilai pendidikan yang terdapat dalam kapamalian tersebut, serta dianalisis unsur-unsur semiotik yang terdapat dalam kapamalian tersebut.

Dari hasil analisis data, kapamalian yang terkumpul digolongkan menurut daur hidup (life cycle) yang terdiri dari urusan nikah, urusan kelahiran, urusan sunat, dan urusan mati. Selain daur hidup (life cycle), kapamalian yang bersifat umum pun termasuk banyak. Kapamalian tersebut dianalisis nilai pendidikan yang terdiri dari nilai moral, nilai sosial, dan nilai agama. Lalu penafsiran maksud lain dari kapamalian tersebut dianalisis unsur semiotik yang terdapat dalam kapamalian tersebut.

\section{Daur Hidup (Life Cycle)}

Kapamalianyang mengatur serta jadi pedoman dalam kehidupan masyarakat di Desa Tanjungwangi digolongkan menurut daur hidup (life cycle), di antaranya urusannikah, urusan kelahiran, urusan sunat danurusan mati. Seluruh kapamaliantersebut digolongkan menurut kegunaan serta siapa yang memakainya. Di bawah ini merupakan hasil dari penggolongan kapamalian tersebut.

Kapamalianyang ada hubungannya dengan urusan kawin, ada 9 (10.2\%) kapamalian yang berisi khusus untuk yang akan dan sudah menikah, yaitu: "Nu rék kawin teu meunang udar-ider, bisi diganggu ku mahluk jahat"(Yang akan menikah tidak boleh bepergian, nanti diganggu makhluk jahat), "Ulah sok dikawinkeun $\mathrm{ka}$ dulur, matak pigoréngeun"(jangan dinikahkan pada saudara, akan menjadi jelek), "Teu meunang patukeur pakéan, matak pahili jodona" (tidak boleh bertukar pakaian, nanti tertukar jodohnya), "Gadis teu meunang ngéndong di mana waé, matak jodona direbut $k u$ batur" (gadis tidak boleh menginap dimana saja, nanti jodohnya direbut orang), "Nu geus kawin teu meunang silihsiaran, teu pantes" (yang sudah menikah tidak boleh saling siaran, tidak pantas), "Nu geus kawin teu meunang ngobrol duaan di jero kamar, bisi paséa"(yang sudah menikah tidak 
boleh ngobrol berduaan dalam kamar, nanti berkelahi),dan "Candoli teu meunang capék rahém kudu saum, supaya lancar dina hajat" (Candoli tidak boleh makan harus berpuasa, supaya lancar dalam acara).

Kapamalianyang berhubungan denganurusan kelahiran, ada 39 (44.3\%) kapamalianyang berisi mengenai kapamalian-kapamaliankhusus untuk ibu mengandung di antaranya "Teu meunang liar ti magrib/salamangsa, bisi dirawu kélong"'(tidak boleh berkeliaran sore hari, nanti diganggu makhluk gaib), "Teu meunang nangunjar, bisi orokna ngalungsar" (tidak boleh duduk selonjoran, nanti bayinya sungsang), "Kudu nganggo bebengkung/gurita, sangkan pianakan merenah deui" (harus memakai kain bebengkung, agar rahim kembali baik), "Teu meunang tuang dina piring gedé, ngarah santenna leutik" (tidak boleh makan dalam piring besar, agar plasentanya kecil), "Teu meunang loba teuing ngadahar lada, matak galak budakna" (tidak boleh banyak makan pedas, nanti anaknya akan galak), "Teu meunang loba teuing ngadahar haseum, matak goréng budi budakna"(tidak boleh banyak memakan asam, nanti anaknya jelek budinya), "Teu meunang ngadahar jambu ku kalong, matak borok pinareup"(tidak boleh memakan jambu bekas kelelawar, nanti menyebabkan radang buah dada).

Kapamalian yang ada hubungannya denganurusan sunat, ada 2 (2.3\%) kapamalianyang isinya berhubungan dengan urusan disunat, yaitu: "Pamali lamun orok awéwé teu digusaran, sok hésé manggih jodo"'(pamali jika bayi perempuan tidak di sunat, akan susah mendapatkan jodoh), "Nu karék di sunat teu meunang ngaléngkahan tai séro, bisi hésé cageurna" (yang baru disunat tidak boleh melangkahi kotoran sero, akan susah sembuhnya).

Kapamalianyang ada hubungannya denganurusan mati, ada 2 (2.3\%) kapamalianyang isinya berhubungan dengan urusan mati, yaitu: "Lamun aya nu maot, teu meunang kuramas, matak ngajakan maot"(jika ada yang meninggal, tidak boleh keramas, sebab akan mengajak untuk mati), "Teu meunang kuramas sareupna, matak maot salamangsa"(tidak boleh keramas sore hari, akan mati sore hari).

Salian dari itu terdapatkapamalianyang bersifat umum, di mana kapamaliantersebut dipakai oleh seluruh masyarakat diluar hal-hal yang ada hubungannya dengandaur hidup (life cycle), yaitu 36 (40.9\%) kapamalian, di antaranya "Teu meunang nyebut embé, kudu uncal kolong" (tidak boleh menyebutkan embe, harus uncal kolong), "Teu meunang nodong dahar dina kastrol, matak rewog barangdahar" (tidak boleh makan langsung dari kastrol, akan rakus dalam makan), "Ulah nyoo péso, bisi cilaka" (tidak boleh bermain pisau, nanti mendapatkan petaka), "Di Gunung Cinini teu meunang gagaro, bisi loba kutu”,(di Gunung Cini dilarang garuk-garuk, nanti banyak kutu), "Teu meunang nginum ditotor tina téko, matak rujit" (tidak boleh minum langsung dari teko, akan menyebabkan jijik).

\section{Nilai-nilai Pendidikan}

Dalam kapamalian tersebut banyak sekali terkandung nilai-nilai pendidikan yang mengajarkan kita untuk berbuat kebaikan dan membawa keselamatan. Seperti yang terdapat dalam nilai pendidikan moral. Ada 42 kapamalian yang termasuk ke dalam kategori pendidikan moral, 16 kapamalian yang termasuk ke dalam nilai pendidikan sosial, serta 13 kapamalian yang tergolong $\mathrm{e}$ dalam kategori nilai pendidikan agama. Dari semua kapamlian tersebut ada 2 kapamalian yang mengandung nilai pendidikan moaral dan agama.

Kapamalian yang termasuk ke dalam nilai pendidikan moral, erat hubungannya dengan tanggung jawab, nurani, serta kewajiban. Beberapa kapamalian yang mengandung nilai moral, di antaranya 
"Ulah diuk dina bangbarung (lawang panto), matak nongtot jodo"(tidak boleh duduk di pintu, nanti susah mendapatkan jodoh),, "Teu meunang liar $t i$ magrib/salamangsa, bisi dirawu kélong"(tidak boleh berkeliaran sore hari, nanti diganggu makhluk gaib),, "Ulah nyoo péso, bisi cilaka"(tidak boleh bermain pisau, nanti mendapatkan petaka), "Teu meunang héhéotan di leuweung, bisi disampeurkeun maung"'(tidak boleh bersiul di hutan, nanti didatangi harimau), "Teu meunang udar-ider, bisi diganggu $k u$ mahluk jahat"(tidak boleh berkeliaran, nanti diganggu makhluk jahat), "Teu meunang ka cai ti peuting, bisi diganggu ku mahluk jahat" (tidak boleh ke wc malam hari, nanti diganggu makhluk jahat). Dari beberapa kapamalian yang mengandung di atas, sangat jelas terlihat nilai-nilai moral yang mendidik kita agar menjauhi hal-hal yang buruk yang nantinya kan memberikan bahaya kepada diri kita.

Di dalam nilai-nilai sosial, yng ditekankan tentunya adalah nilai-nilai yang erat hubungannya dengan masyarakat selaku individu yang tidak hidup sendiri. Beberapa kapamalian yang termasuk ke dalam kategori nilai-nilai sosial, di antaranya "Teu meunang nodong dahar dina kastrol, matak rewog barangdahar"'(tidak boleh makan langsung dari kastrol, akan rakus dalam makan),, "Ulah ngowah coét, matak meunangkeun salaki aki-aki"'(tidak boleh makan dalam cobek, nanti mendapatkan suami kakekkakek), "Teu meunang nginum ditotor tina téko, matak rujit"'(tidak boleh minum langsung dari teko, akan menyebabkan jijik), "Teu meunang diuk dina songsong, matak hitut hareupeun mitoha" (tidak boleh duduk di songsong, nanti kentut di depan mertua), "Ulah sok dikawinkeun ka dulur, matak jadi pigoréngeun"(jangan dinikahkan pada saudara, akan menjadi jelek nantinya). Dari beberapa kapamalian yang bernilai sosial di atas, dijelaskan bahwa kita sebagai manusia harus saling menghormati, saling menghargai, saling menyayangi, dan saling menjaga kesopanan ketika hidup bermasyarakat.

Nilai pendidikan agama merupakan nilai pendidikan yang paling utama, karena merupakan dasar pegangan hidup manusia. Beberapa kapamalian yang mengandung nilai pendidikan agama, di antaranya "Ulah sok nyésakeun sangu dina piring, matak nyésakeun rejeki keur batur”(tidak boleh menyisakan nasi dalam piring, nanti menyisakan rezeki untuk orang lain), "Ulah sasapu ti peuting, matak ngajauhkeun rejeki"'(tidak boleh menyapu malam hari, akan menjauhkan rijki), dan "Lamun aya nu maot, teu meunang kuramas, matak ngajakan maot”(jika ada yang meninggal, tidak boleh keramas, sebab akan mengajak untuk mati). Dari beberapa kapamalian yang distuliskan di atas, sangat tertera jelas nilai-nilai agama yang terkandung di dalamnya. Di sana juga dijelaskan bahwa Tuhan Yang Maha Pengasih sudah mengatur semua rizki yang didapat manusia. Selain itu juga, Tuhan telah menentukan takdir seluruh manusia, baik kematian, jodoh, maupun kebahagiaan. Mak dari itu, kita sebagai manusia harus percaya terhadap segala kekuasaan-Nya. Di alam dunia ini, kita juga diwajibkan untuk menuntut ilmu agar kita selalu diberikan ketentraman hati.

\section{Semiotik}

Di dalam beberapa pendekatan semiotik, dijelaskan bahwa analisis dilakukan menurut unsur ikon, indeks, dan simbol, agar dapat memahami makna dari kapamalian tersebut. Di bawah ini, adalah contoh dari analisis semiotik tersebut.

\section{a. Analisis Unsur Ikon}

Unsur ikon adalah tanda yang dilihat dari objeknya berdasarkan hubungan faktual dan eksistensial antara penanda dan petandanya. (Peirce dalam Sukyadi, 2011, hlm. 217).

Dari hasil analisis, diketahui bahwa ada 28 unsur ikon yang terdapat dalam kapamalian, salahsatunya "Teu meunang nodong dahar dina kastrol, matak rewog 
barangdahar"(tidak boleh makan langsung dari kastrol, akan rakus dalam makan). Dalam konteks ini, kastrol merupakan ikon dari tempat yang dipakai untuk menanak nasi liwet. Jika kita makan dengan menggunakan kastrol sebagai alasnya secara langsung, makan dari tingkah laku tersebut terlihat sebuah sifat rakus. Hal itu disebabkan karena alas yang dipakai, kastrol, jika digunakan untuk alas makan, maka tidak akan terukur seberapa banyak nasi yang dimakan.

Kapamalian"Ulah nyoo péso, bisi cilaka"(tidak boleh bermain pisau, nanti mendapatkan petaka), dalam konteks inipéso digambarkan dengan alat rumah tangga yang tajam fungsinya untuk memotong, dan terbuat dari besi. Alat ini bisa membuat celaka jika alat tersebut terus dimainkan.

Kapamalian "Ulah nguah cowét, matak meunangkeun salaki ka akiaki'"(tidak boleh makan dalam cobek, nanti mendapatkan suami kakek-kakek). Dalam konteks ini kata cowét menggambarkan alat yang digunakan untuk membuat sambel, bentuknya seperti piring kecil, ada yang terbuat darikayu, dan ada juga yang terbuat dari tanah yang dibakar atau yang terbuat dari batu. Oleh sebab itu jika kita nguah cowét disebutkan oleh orang Sunda dahulu akan mendapatkan suami kakekkakek.

Kapamalian "Di Gunung Cinini teu meunang gagaro, bisi loba kutu” (di Gunung Cini dilarang garuk-garuk, nanti banyak kutu). Dalam konteks ini Gunung Cininimenggambarkan gundukan tanah dalam kulit bumi yang banyaknya berjutajuta meter kubik yang berada di Desa Tanjungwangi. Disebutkan oleh karuhun Sunda dahulu bahwa jika kita menggaruk kepala di Gunung Cinini akan mengakibatkan banyak kutu di kepala.

Kapamalian"Teu meunang ngadahar tiwu jeung cangkangna, matak suing"(tidak boleh memakan tebu dengan kulitnya, nanti sumbing), dalam konteks ini tiwumenggambarkan bambu yang mempunyai rasa manis, tajam, dan bisa dimakan sarinya. Oleh sebab itu jika kita menggerogoti tiwu tersebut dengan bagian luarnya akan menyebabkan luka, yang oleh orang Sunda disebutkan dengan suing.

\section{b. Analisis Unsur Indeks}

Indéks yaitu tanda yang bergantung pada denotatum, atau tanda yang menjelaskan adanya hubungan kausal/sabab-akibat (Isnéndés, 2010, hlm.72).

Dari hasil analisis terdapat 35 unsur indéks, beberapa contoh kapamalian yang dianalisis di antaranya "Teu meunang nepak sirah budak/ngadegungkeun, matak calutak ka batur"'(tidak boleh menepak kepala anak, nanti tidak sopan terhadap orang lain). Dalam konteks ini nepak danngadegungkeunmerupakan indeks dari kelakuan yang dikerjakan oleh manusia yang kurang adat tatakrama, kelakuan tersebut akan menyebabkan tidak sopan terhadap orang lain, serta tidak menerapkan prinsip-prinsip adat kesopanan.

Kapamalian "Teu meunang barangdahar bari leuleumpangan, sok kaserang ku hama" (tidak boleh makan sambil berjalan, nanti terserang hama). Dalam konteks ini leuleumpangan(berjalan)merupakan indeks dari kelakuan yang dikerjakan oleh manusia. Dalam hal ini kapamalian tersebut akan menyebabkan pengaruh buruk terhadap tubuh kita, jika kita makan sambil berjalan.

Kapamalian "Nu boga hajat teu meunang mandi, matak hujan badag" (yang punya acara dilarang mandi, nanti hujan besar), dalam konteks ini teu meunang mandi(tidak boleh mandi)merupakan indéksikal dari mandi sama artinya dengan membersihkan tubuh setelah selesainya pekerjaan. Jadi jika sudah mandi, seseorang tidak bisa mengerjakan pekerjaannya lagi (hajat), sebab itu artinya pekerjaan telah selesai. Selain itu ketika mandi, artinya kita meninggalkan acara. Ketika meninggalkan acara, dalam kelangsungannya ditakutkan 
ada bahaya (hujan besar), lalu tidak diketahui oleh kita (yang punya acara), tidak akan ada yang bisa tanggung jawab terhadap bahaya tersebut.

Kapamalian "Teu meunang udar-ider, bisi diganggu $\mathrm{ku}$ mahluk jahat" (tidak boleh berkeliaran, nanti diganggu makhluk jahat), dalam konteks iniudarider(berkeliaran)merupakan indeks dari tingkah laku yang dilakukan manusia, sebab ada yang dicari.Biasanya seseorang yang akan menikah baunya wangi, sehingga dikhawatirkan akan diganggu oleh makhluk jahat.

\section{c. Analisis Unsur Simbol}

Simbol merupakan tanda yang menghubungkan antara tanda dengan denotatumnya yang telah disepakati oleh masyarakat (Isnéndés, 2010, hlm. 72).

Dari hasil analisis terdapat 24 unsur simbol, beberapa contoh kapamalian yang dianalisis di antaranya yaitu "Ulah diuk dina bangbarung (lawang panto), matak nongtot jodo" (tidak boleh duduk di pintu, nanti susah mendapatkan jodoh). Dalam konteks ini bangbarung melambangkan bagian paling bawah pintu rumah yang menghubungkan tiang pintu, terbuat dari kayu, biasanya digunakan untuk keluar masuk orang, atau bisa juga untuk diam, melamun, dan bingung.Jika duduk di bangbarung, biasanya dihubungkan dengan nongtot jodo, katanongtot jodoitu disebutkan untuk seseorang yang susah mendapatkan jodoh, sebab ada yang menghalangi.

Kapamalian "Teu meunang liar $t i$ magrib/salamangsa, bisi dirawu kélong" (tidak boleh berkeliaran sore hari, nanti diganggu makhluk gaib),. Dalam konteks ini kata salamangsa melambangkan bahwa ketika matahari tenggelam makhluk gaib (kélong) mulai berkeliaran. Kélong merupakan hantu yang serupa dengan nenek-nenek yang ada di pepohonan dan berkeliarannya ketika waktu sore. Anak yang senang bermain di waktu sore sering disebut dengan dirawu kélong atau dibawa oléh makhluk gaib. Dirawu kélong itu seperti dililit oleh buah dada kélong yang menggantung.

Kapamalian "Ulah nyiuk béas bari cingogo, matak harkat darajatna handap"(tidak boleh mengambil beras sambil jongkok, akan menurunkan derajat), dalam konteks ini béas melambangkan Dewi Sri yang dihormati sebagai dewi padi. Dewi yang bisa memberikan keberkahan dan rezeki.

Kapamalian "Teu meunang ngalong di panto/jolodog, matak hésé dina ngalahirkeun"(tidak boleh diam di pintu, akan susah dalam melahirkan), dalam konteks ini ngalong melambangan kegiatan yang sedang merasa bingung antara masuk atau tidak. Sebabngalong di pintutentu menghalangi orang untuk keluar masuk rumah, yang akhirnya disamakan dengan susah dalam melahirkan.

\section{SIMPULAN}

Berdasarkan hasil penelitian serta analisis kapamalian yang ada di Désa Tanjungwangi Kecamatan Cicaléngka Kabupatén Bandung, bisa disimpulkan seperti di bawah ini.

Kapamalian yang terkumpul dari 5 narasumber yang ada di Désa Tanjungwangi sebanyak 88 kapamalian.Kapamalian tersebut dideskripsikan arti dan fungsinya, dianalisis nilai pendidikan yang terdapat dalam kapamalian tersebut, serta dianalisis unsur-unsur semiotik yang terdapat dalam kapamalian.

Dari hasil analisis data, kapamalian yang terkumpul lalu digolongkan berdasarkan daur hidup (life cycle)yang terdiri dari urusan nikah ada $9(10.2 \%)$ kapamalianyang berisi khusus untuk yang akan menikah dan setelah menikah. Urusan kelahiran ada 39 (44.3\%) kapamalianyang berisi tentangkapamaliankapamaliankhusus ditujukan untuk yang sedang mengandung. Urusan sunat ada 2 $(2.3 \%)$ kapamalianyang berisi tentang hubungan dengan sunat. Urusan mati ada $2(2.3 \%)$ kapamalianyang isinya berhubungan dengan urusan mati. Selain 
dari daur hidup (life cycle), kapamalian yang bersifat umum pun termasuk banyak, di mana kapamaliantersebut dipakai oleh seluruh masyarakat diluar hal-hal yang berhubungan denganlife cycle, sebanyak 36 $(40.9 \%)$ kapamalian.

Dalam kapamalian tersebut terdapat nilai-nilai pendidikan yang mendidik manusia ke dalam jalan kebenaran dan keselamatan, seperti dalam nlai pendidikan moral sebanyak 42 kapamalian, 16 kapamalian yang termasuk ke dalam nilai sosial. Sedangkan kapamalian yang termasuk ke dalam nilai agama yaitu sebanyak 13 kapamalian. Dalam kapamalian tersebut ada 2 kapamalian yang termasuk pada nlai moral dan nilai agama.

Hasil analisis semiotik diketahui ada 28 unsur ikon, 35kapamalianyang mengandung unsur indéks, sedangkan dalam unsur simbol terdapat 24 kapamalian.

Kapamaliantersebut bukan hanya sekedar istilah yang diucapkan secara bebas, tetapi kapamalian tersebut mengandung nilai-nilai untuk mendidik secara halus agar anak bisa mengikuti apa yang diucapkan oleh orang tuanya. Kapamalian tersebut tidak mengandung arti sebenarnya, tetapi kapamalian tersebut mengandung arti atau maksud lain yang multitafsir.

\section{DAFTAR PUSTAKA}

Danadibrata, R.A. (2009). Kamus Basa Sunda. Bandung: PT. Kiblat Buku Utama.

Danandjaja, J. (2007). Folklor Indonesia: Ilmu Gosip, Dongeng dan lain-lain. Jakarta: Pustaka Utama Grafiti.

Hoed, B.H. (2011). Semiotik \& Dinamika Sosial Budaya. Jakarta: Komunitas Bambu.
Isnendes, R. (2010). Panyawangan Sastra (Handout Teori Sastra). Bandung: JPBD.

Koentjaraningrat. (2009). Pengantar Ilmu Antropologi. Jakarta: PT. Rineka Cipta.

LBSS. (1995). Kamus Umum Basa Sunda. Bandung: Tarate Bandung.

Ratna, N.K. (2010). Metodologi Penelitian Kajian Budaya dan Ilmu Sosial Humaniora Pada Umumnya. Yogyakarta: Pustaka Pelajar.

Ruhimat, A. (2006). Sambel Jaér (Tali Paranti, Palakiah, Kaolahan \& Pantangan Urang Sunda). Bandung: PT. Puspawarna

Santosa, F. 1993. Ancangan Semiotika dan Pengkajian Susastra. Bandung: Angkasa.

Satjadibrata, R. (2005). Kamus Basa Sunda. Bandung: PT Kilat Buku Utama.

Setiyadi, A. (2011). Ajén Atikan dina Sisindiran nu Aya di Désa Parumasan Kecamatan Sodonghilir Kabupatén Tasikmalaya pikeun Bahan Pangajaran Nulis di SMP. (Skripsi). FPBS, Universitas Pendidikan Indonesia, Bandung

Sukyadi, D. (2011). Teori dan Analisis Semiotika. Bandung: Rizqi Press.

\section{UCAPAN TERIMA KASIH}

Terima kasih kepada pengelola jurnal Lokabasa yang telah menerbitkan tulisan ini. Semoga tulisan ini ada manfaatnya bagi perkembangan ilmu pengetahuan. 